DOE/SF/21318-1

\title{
SUPPORT OF ACTIVITIES OF THE NATIONAL ACADEMY OF SCIENCES IN RELATION TO THE RADIATION EFFECTS RESEARCH FOUNDATION
}

\author{
Final Report
}

January 1, 1997 through March 31, 2006

Evan B. Douple, Ph.D.

Nuclear and Radiation Studies Board

The National Academies

Washington, D.C. 20001

May 2006

PREPARED FOR THE U.S. DEPARTMENT OF ENERGY

COOPERATIVE AGREEMENT NO. DE-FC02-97SF21318 


\title{
FINAL REPORT \\ COOPERATIVE AGREEMENT NO. DE-FC02-97SF21318
}

\author{
January 1, 1997 through March 31, 2006
}

During the award period January 1, 1997-March 31, 2006, the National Academy of Sciences/National Research Council (NAS/NRC), primarily through the Board on Radiation Effects Research (BRER), and recently through the Nuclear and Radiation Studies Board (NRSB), has continued its activities related to the long-term follow-up of the health of the survivors of the atomic bombings being conducted at the Radiation Effects Research Foundation (RERF) laboratories in Hiroshima and Nagasaki, Japan. NAS/NRC continued to serve as scientific and administrative liaison between the U.S. Department of Energy (DOE) and RERF and performed tasks in the following program areas: Scientific Oversight, Information/Public Interface, Fiscal Oversight, and Personnel Management. Highlights of work that was supported with extensions by DOE of what was originally a 5-year Cooperative Agreement No. DE-FC03-97SF21318 are summarized in this report, including activities which occurred during the last quarter of this project, January 1, 2006 through March 31, 2006. The highlights are organized with respect to the 4 program areas in the original Statement of Work. Specific activities changed throughout the award period in response to the annual workplan agreed upon between DOE and NAS for each award period, and were dependent upon DOE's requests for no-cost extensions and DOE's available funds.

\section{Scientific Oversight}

- $\quad$ Supported a dosimetry committee The National Research Council formed a Committee on Dosimetry for the Radiation Effects Research Foundation soon after DS86 was introduced and was charged with monitoring the status of DS86 and assessing its relevance in light of any new evidence. The work of the 12-member committee culminated in a 200-page NRC report in 2001, Status of the Dosimetry for the Radiation Effects Research Foundation (DS86), which described the status of DS86. Specifically, that report discussed the key issues and discrepancies which needed to be investigated, outlined some approaches recommended to remedy problems with DS86, and described some preliminary results of experiments which should contribute to an improved dosimetry system for RERF. The report served as a stimulus and guide for intensive efforts by Japanese and U.S. working groups that led to a new dosimetry for RERF, DS02. That improved and revised dosimetry is currently being used by RERF scientists to compute risk estimations.

- $\quad$ Administered dosimetry contracts NAS supported and monitored contracts to SAIC (Dean Kaul, PI) and the University of Utah (Tore Straume, PI), and to a consultant (Wayne Lowder). Those contracts resulted in important computations, measurements, and analyses that contributed to the development of the new RERF dosimetry (DS02). Some funding supported work of Werner Ruehm who identified copper samples in Hiroshima for dosimetric measurements. In addition, NAS recruited a statistician, Harry Cullings, with radiation physics and dosimetry experience, who provided key leadership and expertise to the development of DS02 while serving as a 
member of the RERF Department of Statistics.

- Provided human subjects research compliance NAS monitored the activities of the RERF Human Investigation Committee (HIC), including annual review by the NAS Institutional Review Board (IRB). Dr. Douple served as a liaison for the RERF Project to the NAS IRB and annually updated the DOE Human Subjects Research Database. Major RERF research activities involving human subjects include (1) drawing blood for analyses and exapansion of cell cultures followed by preservation and storage; (2) clinical examinations; and (3) distribution and analysis of questionnaires to A-bomb survivors or to their children. Approximately 60 RERF research protocols (RPs) are currently active and blood samples have been collected from approximately 4,000 subjects each year.

- Supported an Epidemiology/Statistics Partnership In 2005, NAS initiated a contract with the University of Washington and the Fred Hutchinson Cancer Research Center (UW/FHCRC; Scott Davis and Kenneth Kopecky, PIs) which supports a Partnership between UW/FHCRC and RERF. The Partnership enables and facilitates the scientific exchange between RERF scientists and faculty, graduate students, and post-doctoral fellows at UW/FHCRC with the intended goal of providing assistance to RERF in the analysis of data, introducing epidemiologists and statisticians to the rich RERF database and to radiation risk assessment, and to broaden radiation expertise in the epidemiological and statistical sciences including expertise that might be tapped in future recruitments of scientists to RERF. The Partnership has already been successful since during this last quarter the PIs have recruited UW/FHCRC graduate students and faculty who have visited RERF and who are currently finalizing research plans in collaboration with RERF scientists.

- $\quad$ Supported Beebe Fellows A Gilbert W. Beebe Fellowship Program has been established to enable scientists to become familiar with RERF research, contribute to the ongoing analyses at RERF, and to explore potential collaborations with RERF scientists. To date, 4 Beebe Fellows have been recruited who spent various time intervals working at RERF. The current Fellow (Zachary Levinson) concludes his fellowship in May 2006. The goal of providing 12 personmonths of support each year has been achieved, a pool of applicants has been identified, and candidates are being screened for future fellowship assignments.

- $\quad$ Prepared Workplans A series of NAS/DOE workplans were prepared on at least an annual basis in consultation with DOE. Workplans included strategies, goals, and performance measures for the next award period. The workplans were shared with RERF and they were consistent with Academies' activities outlined in agreements between NAS and RERF (i.e., Memorandum of Agreement).

- $\quad$ Nominated Science Councilors and Visiting Directors Each year, accomplished U.S. scientists in disciplines identified as most relevant to RERF's research needs were recruited and nominated to serve as members of the RERF Science Council (5-year terms) and persons with distinguished leadership experience were recruited and nominated to serve as Visiting Directors of the RERF Board of Directors (3-year terms). During this past quarter, Dr. David Hoel was nominated to serve as Science Councilor with expertise in biostatistics (replacing Dr. Clarice Weinberg whose 
term ends in 2006).

- $\quad$ Reviewed the RERF project using advisory committees The NAS conducted regular reviews of the RERF project, formerly using the Board on Radiation Effects Research (BRER), and currently using the Nuclear and Radiation Studies Board (NRSB), and the Academies' Division on Earth and Life Studies (DELS). Distinguished scientists with expertise relevant to the work of RERF are appointed to those advisory committees and are consulted for advice regarding recruitments, scientific expertise, and nominations. Time for a discussion of progress and issues related to the RERF project is included in all board meetings.

- $\quad$ Facilitated collaborations between RERF and U.S. and international scientists NAS staff, including Executive Director Warren Muir, Board Director Kevin Crowley, and Project Director Evan Douple attend meetings of the Science Council and the Board of Directors on a regular basis in order to keep appraised of the latest RERF experimental results, to provide assistance regarding potential needs, and to suggest scientific contacts or potential collaborations that might facilitate RERF research.

\section{Information/Public Interface}

- $50^{\text {th }}$ Anniversary commemorated A symposium was planned and held at the NAS Auditorium in Washington, DC, June 13-14, 1997. The event, “ABCC/RERF: Commemorating the First 50 Years and Looking to the Future,” included both commemorative and scientific sessions. The former included panels made up of former ABCC or RERF employees who provided historical recollections. The scientific sessions included presentations by RERF scientists on current accomplishments at RERF, followed by presentations by invited scientists recognized as experts in the area of focus, and finally followed by a panel of scientists who discussed the future direction of work in specific areas. The areas of focus included risk estimation, non-cancer end points, molecular and genetic basis of cancer, RERF dosimetry, studies of the F1 population, and training collaborations.

- Disseminated RERF results Dr. Douple has submitted manuscripts, made presentations, and prepared and manned information booths at scientific meetings, presented briefings to governmental officials at various agencies and departments, and delivered lectures at various universities in order to promote RERF and to disseminate RERF research results.

- $\quad$ Developed information documents At the request of DOE, three documents were prepared to provide highlights of the RERF work: Health Effects of Ionizing Radiation-A DOE Worker's Guide to the Most Extensive Epidemiological Study in the World; "The Life Span Sudy of the Radiation Effects Research Foundation-Importance, Timelines, and Metrics," and "RERF Research Protocols and Publications During the Period 2000-2003.”

- $\quad$ Distributed RERF publications and other materials Various materials produced by RERF (such as the RERF Annual Report, Update (an RERF newsletter), RERF reports, translations of Japanese news articles, and research protocols) were widely distributed to appropriate mailing 
lists.

- $\quad$ Highlighted RERF accomplishments An annual Gilbert W. Beebe Symposium is sponsored by the NRSB. Although the symposia are not supported using RERF Project funds, special consideration is given to selecting themes, topics, and speakers highlighting contributions and recent results from RERF. A fifth in this series of symposia is currently being planned for November 2006. In addition, an 8-page booklet, Health Effects of Radiation: Findings of the Radiation Effects Research Foundation, was prepared, printed, and distributed widely.

\section{Fiscal Oversight}

- Encouraged development of project-based budgets With the assistance of the Associate Chief of Secretariat, Doug Solvie, and the support of the RERF Financial Supervisor, David Williams, NAS encouraged RERF to develop budgets that reflected actual expenditures by specific projects. NAS and Mr. Williams have also encouraged RERF to improve their timekeeping system and allocate costs appropriately among projects in order to reflect actual expenditures. In addition, we have encouraged RERF to record external grants in the official records and properly record time expended on these grants. NAS has continued to encourage RERF to work with both sponsors in funding the Termination Liability for RERF employees.

- $\quad$ Facilitated acquisition of library journals The purchase of RERF library journals was included as part of an NAS subscription-service contract in an attempt to provide cost savings, improved online access to more journals, and shorter journal delivery times.

- $\quad$ Performed and contracted audits External audits of RERF financial statements were performed under a contract with PriceWaterhouseCoopers (PWC). Those audits were performed until DOE directed NAS to remove the audit function from our budget. Internal audits were conducted by a consultant, paid by RERF, under the direction of Richard Sperry when he was employed at RERF. The internal audits are continuing but are now limited and are being conducted by Doug Solvie. The internal audits are designed to review for unallowable costs as prescribed under OMB Circular A-122.

- $\quad$ Accomplished cost savings The NAS/RERF employee compensation package was reviewed on a regular basis to identify modifications that would provide savings on expenditures. For example, off-site overhead was waived, indirect costs were reduced on all expatriate expenses, a limitation was placed on the term for payment of storage of employee household goods, the term for providing international incentive premiums was reduced and the premiums are now paid as they are accrued, and airfares for NAS/RERF staff were restricted to economy class.

- $\quad$ Prepared budgets At the request of DOE, numerous budgets were prepared for revised award periods and for no-cost extensions in an effort to maintain stability for the RERF program during funding uncertainties.

- $\quad$ Nominated an RERF Supervisor David Williams was nominated to continue serving as the 
RERF Supervisor with responsibility for providing financial oversight. NAS helped to keep him informed regarding fiscal matters and regarding NAS and DOE concerns related to fiscal matters.

\section{Personnel Management}

- Established a Committee for RERF Recruitment In order to assist in the recruitment of research scientists, senior leadership, science councilors, visiting directors, and Beebe Fellows, a 7member committee was formed and supported to provide advice and assistance in recruitment activities for RERF. The committee is chaired by William Schull. The committee conducted its work by meeting once in person and meeting as needed by conference call and it assisted in identifying candidates for the aforementioned positions.

- $\quad$ Recruited NAS/RERF staff Vacancies were filled (subject to availability of funds and approval from DOE) for research scientists, department chiefs, senior leadership positions, associate chief of secretariat, and research librarian. Recruitment activities included development of job descriptions, advertisement, review and ranking of applicants, interviewing of candidates, and contract negotiations. Most recent successful recruitments include a Chief of Research (Roy Shore), an Associate Chief of Research (Thomas Seed), and a Chief of Statistics (Phillip Ross). Current recruitments include two additional statisticians in FY2006 and one epidemiologist in FY2007. The 19 successful recruitments since 1997 are summarized in Table 1.

- Conducted performance evaluations Salary increases for NAS/RERF staff were awarded on the basis of merit which was determined in part using the NAS performance evaluation system. Reviews were conducted each March by NAS/RERF senior leadership and the process was facilitated by NAS staff.

- $\quad$ Personnel and their families were supported Support was provided for all NAS staff and their families at RERF with services such as the acquisition of work visas, income tax preparations, payroll preparation, storage of household goods, relocation arrangements, home-leave arrangements, cross-cultural training, language classes, and arrangements for emergency medical leave when necessary. The services that were provided by contracts (such as payroll and tax services) were monitored by NAS staff. 


\section{Table 1 - SUMMARY OF NAS/RERF RECRUITMENTS SINCE JANUARY 1997 (Bold denotes current employee)}

Person

Seymour Abrahamson

Burton Bennett

Jimmy Cao

Harry Cullings

Eric Grant

Clark Heath

Margaret Irwin

Frederic Lagarde

Donald MacPhee

Michael Morimoto

Phillip Ross

Catherine Sauvaget

Gerald Sharp

Claire Sherman

Thomas Seed

Roy Shore $\underline{\text { Position Title }}$

Associate Chief of Research (01/98);

Vice-Chairman/Chief of Research (07/00)

Chairman (06/01)

Radiobiologist (04/01)

Statistician (10/99)

Research Asst./Epidemiology (12/97)

Associate Chief of Research (01/99)

Information Specialist (09/99)

Statistician (06/03)

Chief of Radiobiology Department (09/99)

Systems Administrator (10/97)

Chief of Statistics (08/06)

Epidemiologist (01/00)

Epidemiologist (11/97)

Statistician (05/97)

Associate Chief of Research (12/05)

Vice-Chairman/Chief of Research (01/06)

\section{Current Status}

Resigned (12/98)

Retired (05/01)

Retired (07/05)

Resigned (07/02)

Statistician

Res. Scientist/Epidemiology

Resigned (12/99)

Resigned (07/03)

Statistician

Retired (09/04)

Resigned (10/99)

Arrival scheduled (08/06)

Resigned (06/05)

Resigned (11/03)

Resigned (07/98)

Associate Chief of Research

Vice-Chairman/Chief

of Research 
Table 2 - SUMMARY OF EXPENDITURES SINCE JANUARY 1997

\begin{tabular}{|c|c|c|c|c|c|c|}
\hline & & $\begin{array}{l}\text { Expenditures paid, } \\
\text { inception to date }\end{array}$ & & $\begin{array}{l}\text { curred, } \\
\text { pending }\end{array}$ & & Total \\
\hline Onsite Expenses & & & & & & \\
\hline Labor plus Iv assessed & $\$$ & $1,507,653$ & $\$$ & (815) & $\$$ & $1,506,838$ \\
\hline Consulting fees/travel & $\$$ & $\mathbf{3 5 , 9 7 3}$ & & & $\$$ & $\mathbf{3 5 , 9 7 3}$ \\
\hline Fringe & $\$$ & 352,349 & $\$$ & (272) & $\$$ & 352,077 \\
\hline Overhead & $\$$ & $1,193,484$ & $\$$ & (770) & $\$$ & $1,192,714$ \\
\hline Travel & $\$$ & 350,825 & & & $\$$ & $\mathbf{3 5 0 , 8 2 5}$ \\
\hline Copying/printing & $\$$ & 28,952 & & & $\$$ & 28,952 \\
\hline Postage & $\$$ & 20,337 & & & $\$$ & 20,337 \\
\hline Long Distance phone & $\$$ & 24,202 & & & $\$$ & 24,202 \\
\hline Tel. Equip chrg & $\$$ & 20,253 & $\$$ & (35) & $\$$ & 20,218 \\
\hline Fax, modem analog & $\$$ & 604 & & & $\$$ & 604 \\
\hline Supplies & $\$$ & 10,343 & & & $\$$ & 10,343 \\
\hline Tech Services & $\$$ & 113,024 & $\$$ & (33) & $\$$ & 112,991 \\
\hline Other direct costs & $\$$ & 9,475 & & & $\$$ & 9,475 \\
\hline Seminars and Training & $\$$ & 29,569 & & & $\$$ & 29,569 \\
\hline Non-travel meeting expenses & $\$$ & 46,078 & & & $\$$ & 46,078 \\
\hline Subtotal, onsite & $\$$ & $3,743,121$ & $\$$ & $(1,925)$ & $\$$ & $3,741,196$ \\
\hline Offsite Expenses & & & & & & \\
\hline$\overline{\text { Beebe Fellowship }}$ & $\$$ & 108,746 & & & $\$$ & 108,746 \\
\hline Subagreements (RERF) & $\$$ & $46,200,000$ & & & $\$$ & $46,200,000$ \\
\hline Subagreements (Partnerships) & $\$$ & 51,036 & $\$$ & 54,586 & $\$$ & 105,622 \\
\hline Subagreements (Dosimetry) & $\$$ & 458,886 & & & $\$$ & 458,886 \\
\hline Accounting fees & $\$$ & $1,004,181$ & & & $\$$ & $1,004,181$ \\
\hline Offsite Payroll (S/W + FB)/unused lv & $\$$ & $6,773,592$ & $\$$ & (688) & $\$$ & $6,772,904$ \\
\hline Incentive Premiums & $\$$ & 75,164 & & & $\$$ & 75,164 \\
\hline Termination allowance offset & $\$$ & $(290,494)$ & & & $\$$ & $(290,494)$ \\
\hline Seasonal allowance offset & $\$$ & $(1,614,080)$ & & & $\$$ & $(1,614,080)$ \\
\hline Tax payments & $\$$ & $1,071,595$ & & & $\$$ & $1,071,595$ \\
\hline Overseas Differential (G\&S) & $\$$ & $2,269,990$ & & & $\$$ & $2,269,990$ \\
\hline Moving/storage & $\$$ & 306,317 & & & $\$$ & 306,317 \\
\hline Cross cultural training & $\$$ & 18,285 & & & $\$$ & 18,285 \\
\hline Home Leave & $\$$ & 177,279 & & & $\$$ & 177,279 \\
\hline Utilities & $\$$ & 162,140 & & & $\$$ & 162,140 \\
\hline Tuition/transportation & $\$$ & 172,012 & & & $\$$ & 172,012 \\
\hline Misc (language training, visa renewals, etc & $\$$ & 208,094 & & & $\$$ & 208,094 \\
\hline Subtotal, offsite & $\$$ & $57,152,743$ & $\$$ & 53,898 & $\$$ & $57,206,641$ \\
\hline General \& Administration & $\$$ & $1,611,449$ & $\$$ & $\mathbf{1 , 5 6 8}$ & $\$$ & $1,613,017$ \\
\hline
\end{tabular}




\begin{tabular}{|c|c|c|c|c|}
\hline TOTAL & $62,507,313$ & 53,543 & $\$$ & $2,560,856$ \\
\hline $\begin{array}{l}\text { Balance of funding in hand, } 5 / 31 / 06 \\
\text { Less expended costs not yet posted }\end{array}$ & & & $\begin{array}{l}\$ \\
\$\end{array}$ & $\begin{array}{r}62,457 \\
(53,543)\end{array}$ \\
\hline Estimated unexpended balance & & & $\$$ & 8,914 \\
\hline
\end{tabular}

